\title{
关於和平利用原子能國际 科学技術会議
}

編者按：1955 年 8 月在日内瓦举行的和平利用原子能國际科学技街会就, 由於美國的阻接, 汥有邀請我國和德意志民主共和國参加。为了帮助我國科学 工作者了解这次会議的情况, 苏联政府特地派遣苏联科学家訪華代表团向我國 科学界進行傳达。苏联科学家代表团在 1955 年 12 月 10 日到达北京, 至 12 月 底及 1956 年 1 月初分別回國。在这时期內，代表团的全体人員廣泛地向我國科 学界作了傳达。这次傅达, 对我國科学家全面了解原子能和平利用情况、促谁 我國的原子能和平利用的研究, 有着重大的作用。这些傳达报告, 將在本刊及 其他刊物分別陸續發表。

苏联科学家訪華代表团团長为 И. И. 諾維科夫教授, 团員有: A. M. 薩馬林 通訊院士、. . H. 克魯日林通訊院士、A. B. 列別金斯基医学科学院通訊院士、 A. M. 庫津教授、M. C. 科传达耶夫博士、B. B. 謝尔比納教授、B. П. 阿傑雅謝 維奇高級研究員、B. H. 科斯雅科夫高級研究員。

\section{原子能与冶金工業}

\section{A.M. 薩馬林通訊院士}

現代科学最偉大的發現之一在技術上的应用得以实現——即指利用原子分裂时放仙 的能量來發电一一是物理学家及工程师們共同努力的結果。如果在探索獾得核子燃料的 最优良方法、結構材料、自动控制線路圆等时所發生的复蓶技術問題不能得到解决, 則 各种类型的核子反应堆的建立就是不可想像的了, 而这些反应堆乃是原子电力站的主要 机件。

原子动力工程的發展向治金業提出了特殊的要求。只有在利用新的制造金屬及合金 过程、应用新設备的基礎上牙可能滿足这些要求。

1. 例如：在現代核子反应堆中廣泛地应用着鋯、鈹及氧化鈹。探索这些材料的制造 方法是需要治金工作者作很大努力的，並且㨁到現在我們还不能認为生迹过程中的某些 細䈱已䌈是最后确定了的。

鈹的㷝点语並具有较好的对許多侵玲性介質作用的抵抗力，所以冶金工作者們早就 注意它了。在确定了鋯具有較小的俘獲热中子截面、因而可以用來做中子減速剂以后,

2 月号

科学通报 


\section{人們对铅就特別注意丁。}

已經确定，在用釷加热方法所得到的鉛中含有雜質，因而不適於在核子动力工程怆

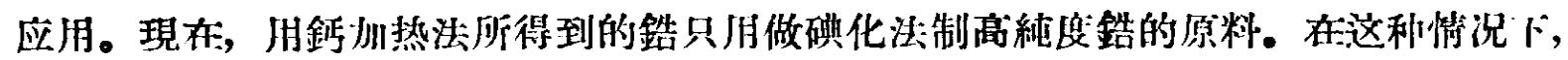
反应空間的压力应达到 $1.10 \times 10^{-4}$ 毫米水銀杜，加热要到反应温度以．50 $500^{\circ} \mathrm{C}$ 。因 此, 只有在使用真空仪器时，才可能制造適於核子反应堆中利朋的鋯。精制鋯的反应本 身的速度也与反应仪器中的压力有关一一在压力为 0.2 毫米水銀杜时速度最大。

从鋯中除去鉿的問題也是很复雜的，因为鉿具有較大的俘獲中子截面。由於铪与鋯 在化学性筫上相近，因而使其难於分离。只有通过偅鋯酸鉀分部結晶的方法才能得栵念 $\mathrm{HfO}_{2}$ 小於 $0.01 \%$ 的二氧化鋯。

鈹及氧化鈹也是利用做中子減速剂的。将工業氯化鈹經过复雜的处理之后，才可能 得含 $0.001 \sim 0.003 \% \mathrm{Fe}, 0.03 \sim 0.007 \% \mathrm{Al}, 0.01 \sim 0.02 \% \mathrm{Si},<0.0003 \% \mathrm{Mn},<0.0005 \%$ $\mathrm{Cu}$ 及 $0.002 \% \mathrm{Ni}$ 的氧化鈹。这种氧化鈹適於在核子动力工程中利用。这利藋化鈹在 $1850^{\circ}-1900^{\circ} \mathrm{C} 、 15-20$ 公斤 $/$ 厘米 ${ }^{2}$ 压力下，在眞空中 $\left(1 \times 10^{-4}\right.$ 寒米 $\left.\mathrm{Hg}\right)$ 加压以后就可

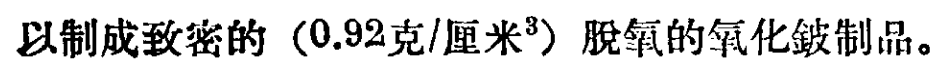

金屈鈹的制造也是很复雜的。即：少將氯化鈹电解制得的鈹在受空中再揢化，去掉 揮發性雜質, 再於氞气氛中 $\left(20\right.$ 毫米 $\mathrm{Hg}$ ) 淮行焀化, 温度是 $1500-1550^{\circ} \mathrm{C}$ 。比較更純的 鈹是把工業鈹在真空中蒸餾得到的。蒸發是在 $1300-1400^{\circ} \mathrm{C}$ 、剩余压力約 $1 \times 10^{-5}$ 毫米 $\mathrm{Hg}$ 下進行的。

虽然如此，用鎄鈹制成的制品是脆的，其机械强度不湍。为了制造適於反应堆中使

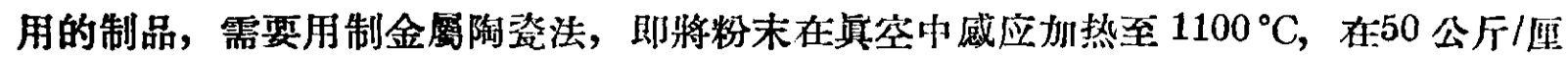

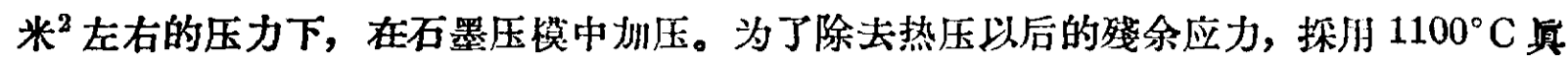
空退火，随后緩烚。

这里引用了一些制造用於核子反应堆的鋯、鈹及氧化鈹等的工蕉过程的知識，目的

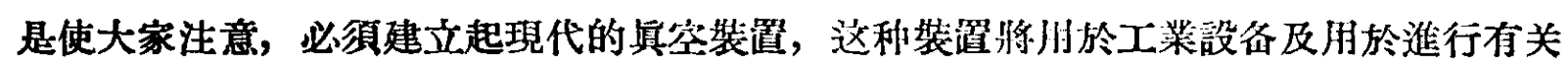
的科学䂰究。

2. 發展核子动力工程要求搌大高合金鎆与合金鋼的生產。

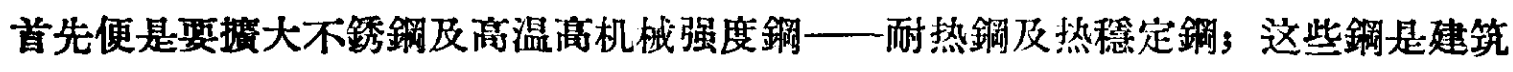
桡子反应堆及原子發电站所必需的。

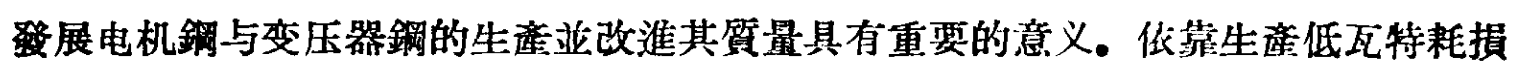
的电工用鋼的方法可以达到降低电动机及变压器的重髲、在國比經济中大大減少电能損 失.

没有精密仪器制造, 就不可能順利地發展核子动力工程, 而精密仪器制造的發展就

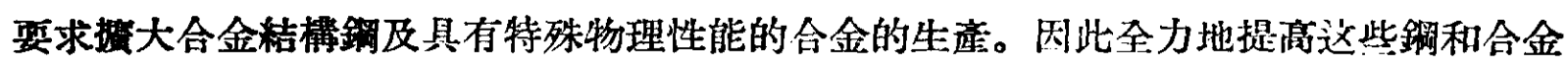

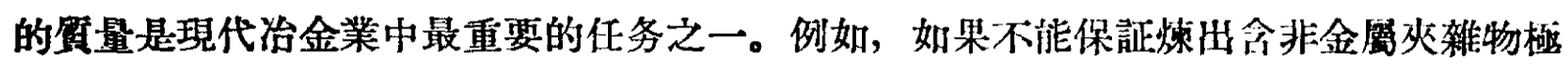
低的滚珠軸承鋼，便無法保詿現代仪器用軸承的制造。

由於合金鋼及禹合金鋼生立的發展，中國的冶金工作者应該注意挆索那样的一些鋼， 它們除了能滿足对它們所提出的要求，並且它之所以們得到这些必䋢的性能，首先是依 靠在这些鋼中存在着中國所不缺乏的合金元素。以利月中國的天然資源为基礎創造新堸 
种及新型合金的工作应該是中國科学机構最基本的与首要的任务之一。

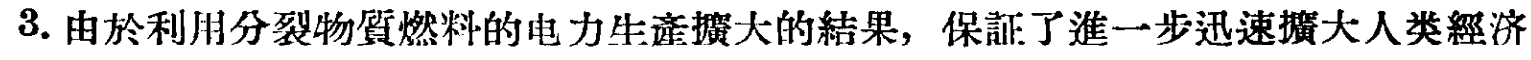
活动力而的动力尃源。然而, 如果沒有高度發展的治金工業的存在, 这个偉大科学發現

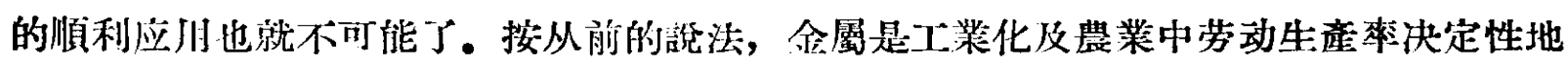
提高的基礎。改淮黑色冾金業中現在泣川的过程肦探索新的过程的工作能够保訴大力地

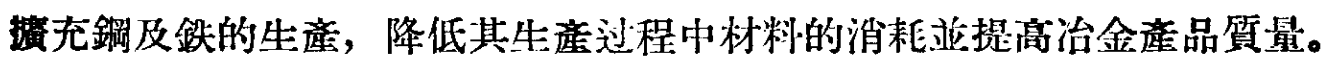

㩜大生鉄的冶煉, 就必定要引起应用含鉄较低或含雜質較高的鉄礦到生座中的問題。 因此，研究國家各礦座地鉄礦的选磺过程就是迫切需要的了。

按照鞍山鋼鉄公司的工作成績來制断，中國的冾金工作者現在在基本治金設备的㙅 作方面都已达到很高的指标了。

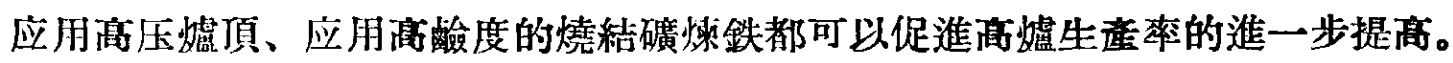

需要組絿一些研究工作，以便确定是否可能用造塊方法來代替鉄磺燒桔法。鉄礦、

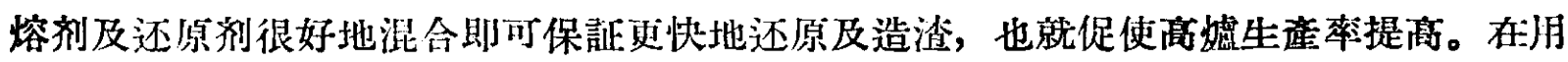
新造洗法时可能还会降低煉焦煤的消耗量。

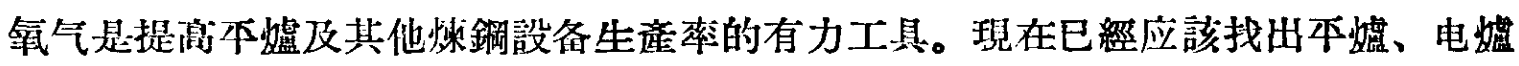
及轉㠊中应用氮气煉鋼的最合理的方法。[在建汒獲得氮气的裝置时, 必須考慮合理地利

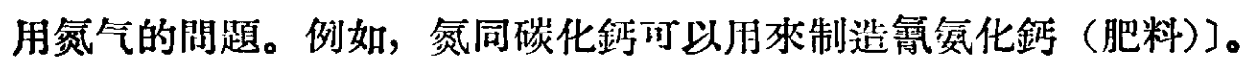

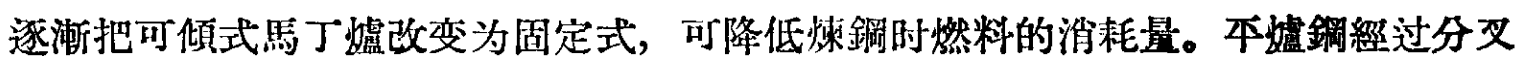
的出鋼槽出鋼可以降低休嘘, 当有一定举重能力的吊車时, 还能坦大嘘子的容積。

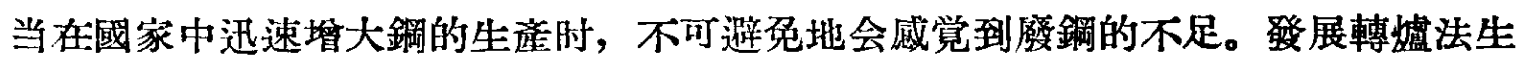

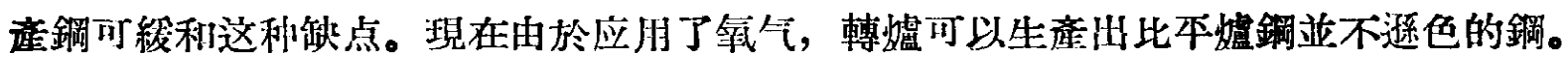

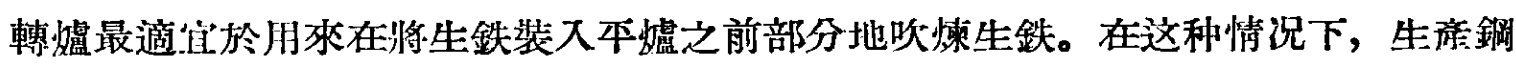
所需燃料的消耗可以降低, 本嘘的生產率可以提语, 造渣材料的消耗可以降低, 所需度 踻的数量而以減少。

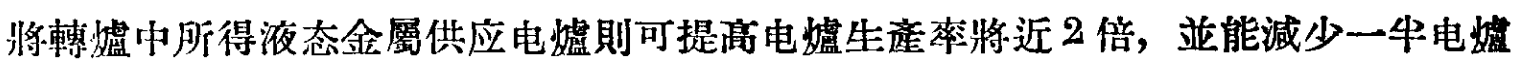

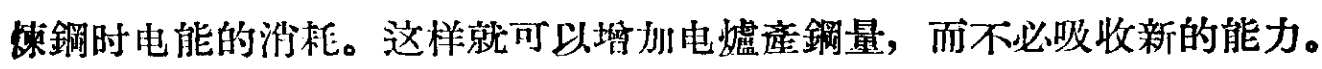

把以前留用过的設备开动起來，用來生產熟鉄塊是很合適的，因为熟鉄塊可以用來 代替愿鋼，或是用做高嘘嘘料中的填加物。

还可靠捉润鋼的合格產品來燳加鋼的生產。因此便应該注意在工業实踐中应用連縝

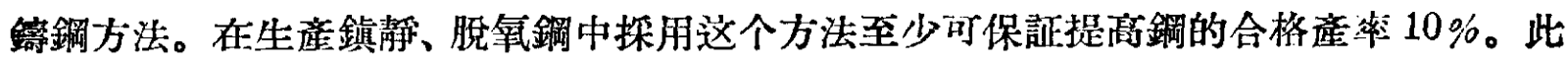
外，由於在边程中完全可以不用各式䡉鋼机，因而也改善了鋼的加工流程。連䌅鋀鋼机

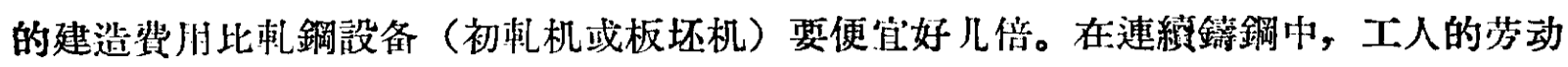
条件也大有改善。

提高鋼的質量，降低鋼生產中的廢品，这些都是摭大治金生產成品的重要手段。

由於改進生道过程, 可以保証煉出的鋼含雜質最低, 得到的鋼錠具有均一的化学組 成。应用各利方法在基空中处理各利嘘子中煉出的鋼液可以獾得性能較好的鋼。在悬空

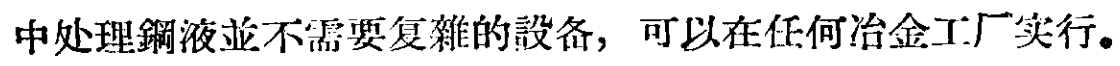

使鋼与某些元素制成合金的方法可能会大大提高鎆的質量。已縃部实：釩对深拉用

2 月号

科学通报

- 87 • 
沸腈鋼的性能有良好影响。希土元菜可以大大改進許多高合金鋼的工基性能。

4. 物理学家們不只对冾金工作者提出了新的要求，而他們也用新的工具武裝了冶金 工作者們，这些新的工具可以使我們迅速地解决治金生革中的許多重要問題。

应用人造放射性同位素，即“示踪”原子，治金工作者們就可以進行一些以前完全不 可能的科学研究工作。

“示踪”原子現在已廣泛地被利用在研究冶金反应及过程的动力学上，当然，这些研 究的結果都是强化治金生童的科学根据。

目前，各利控制冶金生產的新方法都是以应用放射性的輻射为基碳的。例如，現在

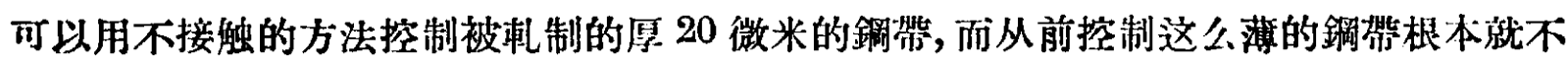
可能。如果要量一下, 就要停止軋制, 而以后再开动机床时, 鋼圌就要断裂。

由於利用人造放射性同仙素，冶金生着过程自动化的工作也容易多了。已可以連縸

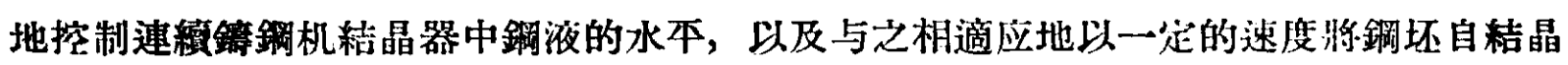
器拉出, 些隻行二次冷却。

在制造超純度的金屬时，只有利朋放射性的分析方法才可能测定極小量的雜罂， 利用一般的化学分析方法, 这利測定是不河能的。

随着原子动力工程的發展, 在中國的冶金工作渚面前㨽着一些复䆶的問題, 但是, 如果考虑到他們拥有的新工具，考慮到中華人民共和國政府对科学的發屡所給予的关怀 的話，我們就知道，中國的治金工作者一定能順利地解决这些䦌題的。

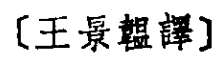

\section{〔上接 84 頁〕}

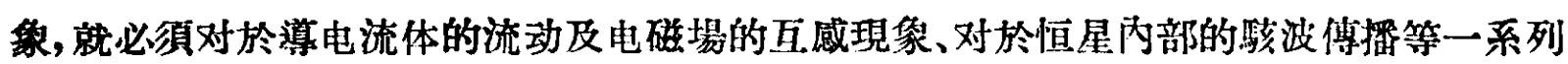
近代流体力学閣題有深入的研究, 这些方面对於㞗际物筫的运动及变化有十分密切的关

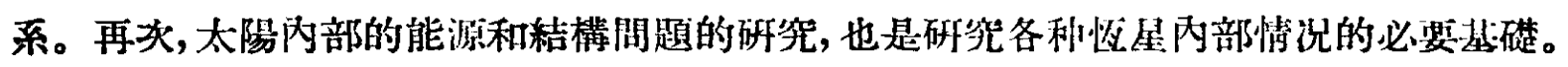

由以上各点可見, 开展上述二尃題的研究, 把这二專題的㸴究在三、五年內提到一 定的水平, 是打好天体物理学研究的基磷的一条可行的道路。为了这一工作所建立的光 学实驗室和电子学实驗室将在天体物理学研究工作上起巨大的作用。

在三、五年后，我們有了較好的光学实驗室及电子学（尃为天文愔用而設的）实驗 室, 再進行用大远鏡研究特殊恆星、用超短波研究星际物筫等工作就比較地容易了。作这 几方面的工作，要大远鏡及大天綫系統。在我看秝，250 厘米胪徑的远鏡在十年、二十 年之內是应該建成的。大天綫也是如此。但是更要緊的, 是將收集到的輻射進行良好的 分析。做到这一点的根本条件是在進行建立太陽物理学工作中要比实提高基礁技術及理 論的水平。

我覚得“赶上國际先淮水平”不同於“跟上因际先進水本”, 当我們赶上了國际先淮水

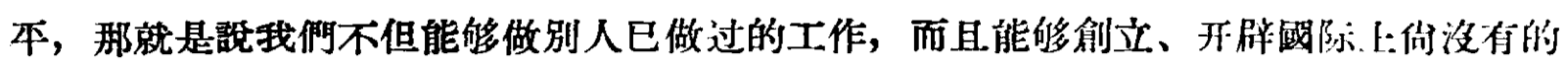

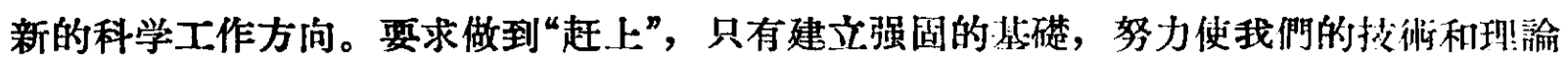
达到國际水平, 即是达到一个可以自由开展新工作的境界。如果我們只着腿於“跟.E.”, 那 就不免总是落后一步，总是跟在別人后面。 